ISSN: $2594-4827$

\title{
METODOLOGIAS ATIVAS NO ENSINO DE GRADUAÇÃO: UMA EXPERIÊNCIA EM DISCIPLINAS PROJETUAIS NO CURSO DE GRADUAÇÃO EM TÊXTIL E MODA DA UNIVERSIDADE DE SÃO PAULO
}

\author{
Beatriz Ferreira Pires ${ }^{1}$ \\ Cláudia Regina Garcia Vicentini ${ }^{2}$ \\ Suzana Helena de Avelar ${ }^{3}$ \\ Recebido em: março/2020 \\ Publicado em: agosto/2020
}

\section{RESUMO}

Nas disciplinas que envolvem o fazer projetual em cursos de graduação tais como: design, engenharia e arquitetura, há uma constante preocupação do aluno em relação às atividades que envolvem criatividade e inovação. Isso se deve em parte à crença originada do senso comum de que há algumas pessoas que são gênios e outras, simplesmente não são e nunca alcançarão um nível de excelência satisfatório. Essa crença generalizada acaba por prejudicar o desempenho de estudantes nas disciplinas em que é necessário que o aluno se coloque como protagonista na construção de seu conhecimento, assumindo riscos e aventurando-se.

Mas, além disso, corroboram para este estado de coisas os métodos tradicionais de ensino a que os alunos são submetidos desde a pré-escola até o ensino médio que não os preparam para estes tipos de desafios, uma vez que são formados para receber os conteúdos e não para discuti-los e problematizá-los contextualizando-os na realidade.

Porém, o cerne destas profissões é o ato de projetar, está é a finalidade de sua formação. Quer sejam sistemas, produtos, veículos, vestuário ou calçados, se pretende que haja inovação, pois hoje, mais do que nunca é preciso rever conceitos de produção e consumo, face as questões relativas à desigualdade social, sustentabilidade, inclusão, entre outros que são assuntos que requerem novas visões de mundo.

Refletindo sobre essa problemática experimentamos na disciplina de Design de Acessórios de Têxtil e Moda da graduação em Têxtil e Moda a utilização da metodologia ativa centrada no Aprendizado Baseado em Projeto. O resultado mostrou-se muito satisfatório gerando 4 (quatro) patentes de produto desenvolvidos em conjunto com um grupo de alunas do curso.

Palavras-chave: Educação; criatividade; tecnologia; metodologias ativas.

\footnotetext{
${ }^{1}$ Escola de Artes, Ciências e Humanidades - EACH - USP. E-mail: beatrizferreirapires@usp.br

${ }^{2}$ Escola de Artes, Ciências e Humanidades - EACH - USP. E-mail: claudiagarcia@usp.br

${ }^{3}$ Escola de Artes, Ciências e Humanidades - EACH - USP. E-mail: suzana.avelar@usp.br
} 
ISSN: $2594-4827$

\title{
ACTIVE METHODOLOGIES IN UNDERGRATUATE EDUCATION AN
}

\section{EXPERIENCE IN DESIGN DISCIPLINES IN THE UNDREGRADUATE COURSE IN TEXTILES AND FASHION AT THE UNIVERSITY OF SÃO PAULO}

\begin{abstract}
In the disciplines that involve project design in undergraduate courses such as design, engineering and architecture, there is a constant student concern regarding activities involving creativity and innovation. This is partly due to the commonsense belief that there are some people who are geniuses and others who simply are not and will never achieve a satisfactory level of excellence. This widespread belief ultimately undermines students' performance in the disciplines where the student needs to be the protagonist in building their knowledge, taking risks and venturing out. But furthermore, the traditional teaching methods to which students are subjected from preschool to high school that do not prepare them, or these types of challenges corroborate to this situation as they are trained to receive the content. and not to discuss and problematize them by contextualizing them.

However, the core of these professions is the act of designing, this is the purpose of their formation. Whether they are systems, products, vehicles, clothing or footwear, if innovation is to be sought, because today, more than ever, it is necessary to review production and consumption concepts in the face of social inequality, sustainability, inclusion, among others. subjects that require new worldviews.

Reflecting on this issue, we experienced in the Textile Accessory Design and Fashion discipline of the undergraduate degree in Textile and Fashion the use of the active methodology based on Project Based Learning. The result was very satisfactory generating 4 (four) product patents developed in conjunction with a group of students of the course.
\end{abstract}

Keywords: Education; creativity; technology; active methodologies.

\section{INTRODUÇÃO}

A sociedade contemporânea tem sido testemunha de uma grande, e cada vez mais acelerada, mudança nas formas de trabalho. Convivem lado a lado, gerações muito diferentes em suas relações homem-trabalho. Se por um lado há uma geração mais velha e tradicional, criada em um mundo analógico, em que a carreira profissional era vista como um projeto para toda vida, há uma outra geração, mais nova, que vê a relação com o trabalho de forma diferente, mais fluida e flexível, devido em parte às mudanças de mercado, e também dos modos de vida. Em meio a estas mudanças comportamentais surgiram em meados dos anos 1990 o que ficou conhecido como as indústrias criativas, em que o produto tem grande valor simbólico e de difícil mensuração, como no design, na arte, no entretenimento, em softwares e na moda. 
É muito comum neste segmento a ideia de uma "vocação", em que é desejável possuir um "talento" para a execução do trabalho. É exatamente neste contexto que se dá a problemática levantada neste estudo. Os cursos de nível superior que embasam estas profissões têm como core competence o fazer projetual que auxilia neste trabalho que se aproxima do ofício do artesão, carregado de significados em que o fazer manual mistura-se ao industrial.

Por outro lado, é necessário dizer que uma vez inseridos na lógica de mercado, esse fazer híbrido de manual e industrial, busca a inovação que poderá manter a competitividade e sobrevivência das empresas.

O ensino superior no Brasil mostrou uma mudança nos últimos anos com o surgimento de vários conglomerados educacionais particulares, e dos programas de auxílio à permanência estudantil como o PROUNI e o FIES, possibilitando à uma grande parcela da população brasileira que não tinha acesso à educação, poder ingressar em cursos superiores. Por outro lado, houve a expansão das Universidades Federais e a integradora política de cotas, que também aumentaram esses números. Há, claro, uma extensa discussão sobre a validade destes acessos, da democratização do ensino superior, e segundo Barbosa (2015) há uma diferença entre democratização e massificação, já que nem todas as categorias sociais se beneficiam da mesma forma.

De qualquer maneira este acesso acontece justamente em um momento de crise de identidade das universidades brasileiras, tanto públicas quanto particulares, mas, acreditamos, uma crise que atinge com mais força as universidades públicas, no que diz respeito ao qual seria o seu verdadeiro papel na sociedade. Neste sentido é pertinente dizer que o Brasil, assim como outros países da América Latina mantém dependência econômica e cultural externa, principalmente de países mais desenvolvidos economicamente. Nestes moldes os papéis universitários brasileiros se alternam entre modelos de resistência a essa dependência e outros que se coadunam com ela.

A história nos mostra que se em seu início, no Brasil, as universidades traziam a ideia da formação de profissões, em que o aluno ao cursar uma faculdade específica conquistava o direito de exercer determinada profissão, em meados do século XX o modelo Humboldtiano, adotado ainda que parcialmente no país, incorporou a pesquisa a essa prática, a fim de unir ensino e pesquisa. (BOTTONI; SARDANO; COSTA FILHO, 2013) 
É sabido que as universidades brasileiras foram criadas como forma de produção de conhecimento, notadamente nas áreas de ciências e tecnologias, avançado mais tarde para as áreas de ciências humanas, principalmente com a criação da USP- Universidade de São Paulo e da UDF - Universidade do Distrito Federal. O que também podemos inferir é que com as crises políticas, estado novo, depois golpe militar, o papel social destas instituições foram mudando, assumindo um protagonismo político de resistência, muitas vezes. Isso, sem dúvida teve impacto na criação de currículos às vezes suprimindo conhecimentos em meio a um processo de censura no regime militar e, por outro lado, o aporte financeiro em pesquisas das áreas tecnológicas. Após o fim do regime militar as Universidades puderam gerir melhor seus recursos e investimentos também em outras áreas do conhecimento.

Isso posto nos perguntamos: e qual seria o papel da universidade frente ao mercado? Uma reflexão necessária diz respeito a "importação de conhecimentos" nas universidades, ou seja, a adoção de modelos que são muito bem aceitos em outras culturas, especialmente as mais desenvolvidas economicamente, mas que muitas vezes não tem aderência aos costumes e formas de pensamento latino-americanos em especial, os brasileiros.

Estas questões permeiam o ensino de nível superior de maneira geral, mas especialmente em cursos novos, como os de design são bastante pertinentes. Face aos grandes problemas ambientais e sociais que afligem o mundo como um todo, deve-se colocar em pauta discussões desta natureza, já que preceitos anteriormente aceitos, como o consumo despreocupado não fazem sentido no mundo em que vivemos, desta maneira os atuais os atuais educandos são os profissionais de amanhã que poderão de alguma maneira repensar estes modelos.

\section{A PROFISSIONALIZAÇÃo DO SETOR ECONÔMICO LIGADO A PRODUÇÃO DE VESTUÁRIO}

O Brasil foi durante muito tempo um grande produtor de algodão, o que resultou na formação de polos beneficiadores do algodão e consequente formação de pequenos conglomerados industriais têxteis especialmente no final do século XIX e começo do século $\mathrm{XX}$. Em paralelo a isso o setor de vestuário após a primeira guerra mundial também ganhou fôlego, mas foi a partir da década de 1940 que a indústria de confecção de roupas cresceu de fato. Com uma grande imigração de europeus para o Brasil, especialmente judeus que se estabeleceram no bairro do Bom Retiro em São Paulo, pequenas confecções de roupas 
começaram a surgir e foram crescendo para o bairro do Brás e com incentivos fiscais tornaramse pequenas e microempresas.

Caracterizado por ser um tipo de trabalho em que não havia necessidade de mão de obra especializada, nem tampouco maquinário caro, este setor da economia cresceu rapidamente e se expandiu também para outras partes do país. Vários polos industriais têxteis se consolidaram tais como: as cidades de São Paulo e Americana no estado de São Paulo, Blumenau e cidades vizinhas em Santa Catarina formando um grande centro produtor de malharia circular, Friburgo no Rio de Janeiro, Santa Cruz do Capibaribe em Pernambuco, Fortaleza, Monte Sião e as cidades próximas do sul de Minas Gerais no setor de malharia retilínea, só para citar alguns.

Na década de 1970 foram criadas Feiras Têxteis como a Fenit para consolidação do setor, que sob comando da multinacional Rhone-Poulanc a Rhodia fabricante de fios sintéticos percebeu o grande potencial consumidor do Brasil.

A partir da década de 1980 o setor já bem estruturado e bastante competitivo viu aumentar a demanda por uma mão de obra especializada que atendesse as necessidades das empresas nos setores de criação e produção. Com o surgimento das Semanas de Moda como o Phytoervas Fashion e Morumbi Fashion que lançaram grandes nomes da moda brasileira e que hoje está consolidada na São Paulo Fashion Week atraindo visitantes do mundo todo, a necessidade de profissionais ficou ainda mais evidente.

Neste cenário foram criados os primeiros cursos de nível superior em Moda. A universidade AnhembiMorumbi que hoje pertence ao grupo Laureate, foi a pioneira no setor. Vários cursos de graduação foram surgindo a fim de oferecer embasamento para este profissional que era requisitado pelo mercado. Com abordagens mais humanísticas com ênfase no ensino da arte como foi o caso do curso oferecido pela Faculdade Santa Marcelina ou voltado para negócios como a graduação da AnhembiMorumbi, passando por especializações em técnicas de modelagem e criação, um grande leque se abriu e muitas oportunidades de formação surgiram.

Hoje são muitos cursos de nível superior espalhados pelo Brasil contribuindo para a consolidação da área.

Porém, junto a essa grande oportunidade também surgiram as dificuldades em se lidar com um mercado extremamente competitivo e volátil. A busca por processos e produtos inovadores tem sido uma preocupação constante, e essa demanda abriu espaço para a pesquisa 
acadêmica tanto na área têxtil, como por exemplo em processos químicos, desenvolvimento de novas fibras, acabamentos, tingimentos, tratamentos de efluentes, processos de produção, logística, controle de qualidade, como também na área da moda sobre consumo, comportamento, história, criação, desenvolvimento de produtos, psicologia do consumidor, marketing, administração entre outras.

\section{METODOLOGIAS ATIVAS DE ENSINO-APRENDIZAGEM - PBL - PROBLEM BASED LEARNING}

Na esteira deste pensamento a Universidade de São Paulo também passou a ofertar a partir de 2005 o curso de bacharelado em Têxtil e Moda na Escola de Artes, Ciências e Humanidades. A estrutura desta unidade conta com um ciclo básico de formação geral para todos os dez cursos ali existentes e um dos norteadores do projeto pedagógico institucional, se podemos chamar assim, é a disciplina de Resolução de Problemas comum a todos os cursos. Esta disciplina baseia-se no conceito conhecido como Problem Based Learning. Esse método insere-se no âmbito das metodologias ativas de ensino-aprendizagem em que o educando é estimulado a protagonizar seu aprendizado sob a orientação de um professor. Segundo Andrade e Campos (2005) este método contribui para a independência de pensamento do estudante, desenvolvendo sua capacidade crítica e autonomia. O surgimento do PBL foi na Universidade de McMaster em Ontário, na área de medicina entre os 1960 e 1970 e depois foi adotado em outros países, dado seu bom resultado.

O PBL tem tido bons resultados em áreas essencialmente técnicas, pois como já se sabe, as disciplinas das áreas de exatas, e mesmo as mais voltadas a formação de profissionais técnicos tem dificuldade em inserir em seus currículos conhecimentos da área de humanidades. É claro que isso decorre, em parte, pela própria vocação daqueles que procuram estas áreas, mais voltadas ao saber-fazer. Porém, em sociedades cada vez mais complexas é de fundamental o conhecimento das áreas de humanidades na construção de saberes interdisciplinares, já que estes são requisitados a fim de que o profissional possa dar conta das inúmeras demandas oriundas dessa complexificação, e porque não dizer, também refletir criticamente sobre seu papel na sociedade, como profissional e indivíduo, catalisador de mudanças de pensamento e comportamento. 
Faz parte do escopo da disciplina definir um "problema" relacionado ao tema a ser estudado. São formados grupos de alunos e estes são estimulados a organizar suas tarefas de coordenação do processo de busca de informações, planejamento do tempo, e a distribuição de tarefas entre os membros do grupo. Com prazo máximo de 15 (quinze semanas) eles procuram a figura do professor como tutor de seus trabalhos, a fim de elucidar dúvidas. Também são estimulados a utilizarem os meios digitais como forma de manterem-se conectados para o bom andamento do trabalho. É neste cenário que metodologias como PBL fazem sentido uma vez que sua proposta é trabalhar a interdisciplinaridade e a construção de autonomia do educando.

\section{METODOLOGIA}

Foi aplicado na disciplina de Design de Acessórios de Têxtil e Moda em 2014 uma metodologia híbrida que mesclou conceitos pedagógicos de ensino-aprendizagem do PBL e do ensino projetual metodológico para o desenvolvimento de produto.

Eram objetivos da disciplina fomentar no educando o desejo de investigação relativo ao tema abordado, introduzir conceitos técnicos relativos à manufatura de calçados artesanais, estimular a prática de trabalho em grupo, e a interdisciplinaridade, ao lidar com problemas reais oriundos do ato de se projetar algo para alguém.

O ensino de desenvolvimento de produto tem um escopo bastante definido nas áreas de engenharia, arquitetura e design. Basicamente é ensinado ao aluno uma metodologia, uma espécie de passo a passo, que procura abranger e propor alternativas para os diversos problemas decorrentes no processo.

Muitos autores têm se ocupado e proposto alternativas metodológicas que visam auxiliar a difícil tarefa que é desenvolver produtos atualmente. (SANCHES, 2018; RECH, 2003; VICENTINI, 2010; BACH, 1983). Porém, temos notado uma carência de estudos que busquem identificar e propor alternativas para o ensino desta temática, a fim de fomentar no educando e futuro profissional, as competências necessárias para lidar com a complexidade da área. Nas Diretrizes Curriculares Nacionais do Curso de Graduação em Design, segundo Martins e Wolff (2015) a importância do projeto é ressaltada e uma das competências exigidas é uma visão sistêmica do projeto que é manifestada por meio de componentes materiais e também intangíveis tais como: processos fabris, aspectos econômicos, psicológicos e simbólicos do produto, e o segundo, ter domínio das etapas do desenvolvimento de um produto que dizem 
respeito ao conhecimento de público-alvo, definição de objetivos, técnicas de coleta e tratamento de dados, geração e avaliação de alternativas, configuração de solução e comunicação de resultados.

Especificamente na área de moda o "projetar" é constituído por etapas, que envolvem uma série de pesquisas: público-alvo, tendências (cores, formas, acabamentos, para uma determinada estação), vocações regionais, e por fim o tema que norteará a coleção. Uma vez definidos estes parâmetros, são feitos os esboços (croquis), custos, plano de compras, confecção e seleção dos protótipos e confecção do mostruário. (VICENTINI; DEDINI, 2009).

Esta sistemática deriva de saberes empíricos em que o fazer foi sendo sistematizado, a fim de se tornar um processo que pudesse ser seguido, e principalmente repetido. Ainda há uma grande valoração de algo ligado a uma "intuição" do designer, ou seja, seu conhecimento de mercado, mas ainda pensa a roupa de maneira quase artesanal como faziam as costureiras de antigamente que costuravam para uma pessoa, de forma personalizada. $\mathrm{O}$ processo de fazer a roupa, incluindo a concepção e sua materialização gráfica no desenho era feito por uma única pessoa. Com a industrialização, este saber (ou fazer) artesanal foram incorporadas informações, a fim de torná-lo atrativo a um número maior de pessoas (clientes). Assim as indústrias começaram a fazer pesquisas de tendências de cores, formas, e detalhes apresentados nas passarelas de estilistas renomados, que poderão ser aproveitados para integrar a coleção, e tornar o produto mais atrativo a seus clientes. (VICENTINI; DEDINI, 2009)

No caso de nosso estudo buscamos, como já dissemos, combinar os conceitos do PBL, metodologia projetual de Vicentini (2010) e de projeto modular no ensino de design de produtos.

O conceito de projeto modular (MARIBONDO, 2009) pode ser entendido como a ideia de criar produtos que possam ser recombinados em arquiteturas diferentes das originais gerando assim novos produtos. A modularização pode ser total ou parcial. Muito utilizada para o projeto de automóveis e seus componentes, essa metodologia também é utilizada de maneira informal em outras áreas. $\mathrm{Na}$ área de calçados já há alguns produtos que seguem estas definições, em termos de possibilitar a troca de salto, ou de um adereço, entre outros.

A metodologia projetual utilizada foi alterada em algumas das fases por se considerar que não haveria a fase de produção industrial, ficando apenas em escala laboratorial. (VICENTINI, 2010) 
A decisão de utilizar apenas parte da metodologia foi importante por considerar a questão didática em que era esperado que se desenvolvessem as habilidades projetuais dos alunos. A metodologia completa foi utilizada em ambiente fabril, considerando todas as etapas de desenvolvimento de um produto, desde o briefing inicial, passando por levantamento de dados, criação, prototipagem, custos, execução e distribuição, etapas estas, que fogem do escopo da disciplina.

Deste modo temos que a primeira fase da metodologia empregada ficou como está colocado nas figuras 1 e 2 - Estudo de viabilidade: as informações sobre público-alvo são levantadas e compiladas de modo a serem utilizadas como parte dos requisitos de projeto.

Assim, temos que o projeto de produtos voltados ao vestuário e acessórios tem em seu escopo projetivo a escolha de um tema, que dará unidade visual à coleção de produtos, uma vez que dificilmente serão projetadas peças únicas, com exceção da alta costura que abrange um outro segmento da sociedade e não será analisada neste artigo.

Figura 1 - Metodologia para o desenvolvimento de produtos.

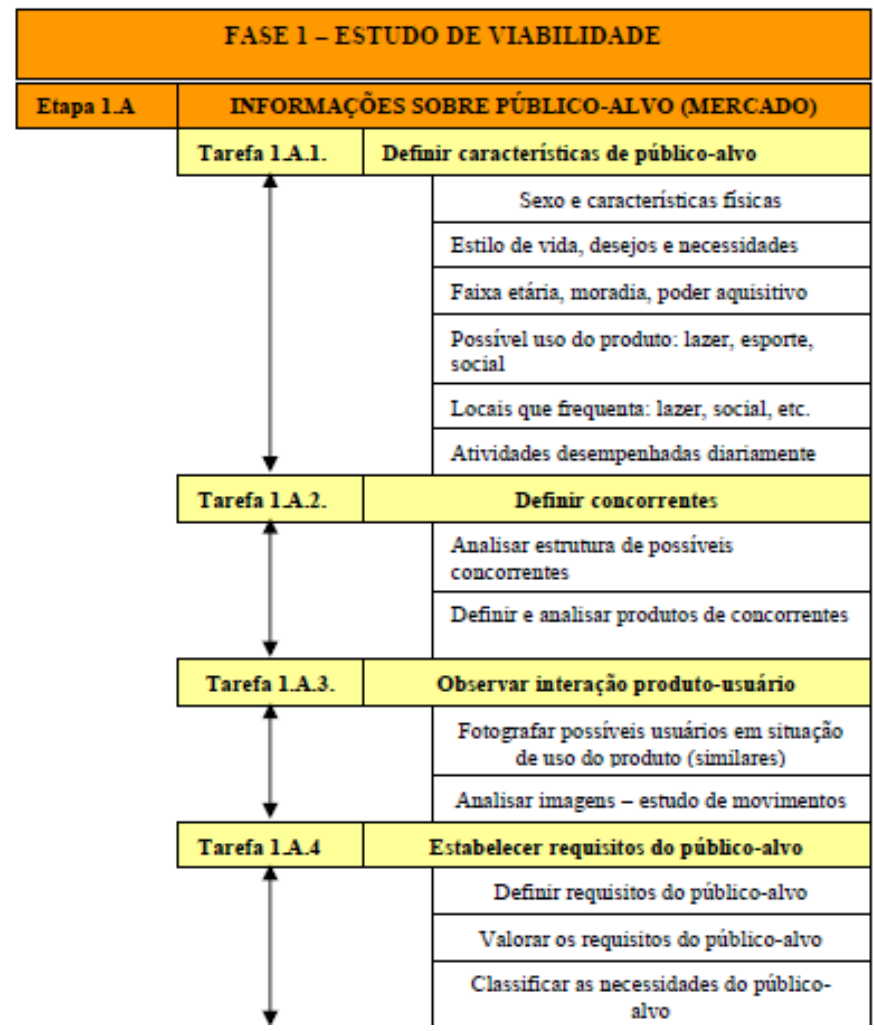

Fonte: adaptado de Vicentini (2010) 
Figura 2 - Metodologia de Projeto

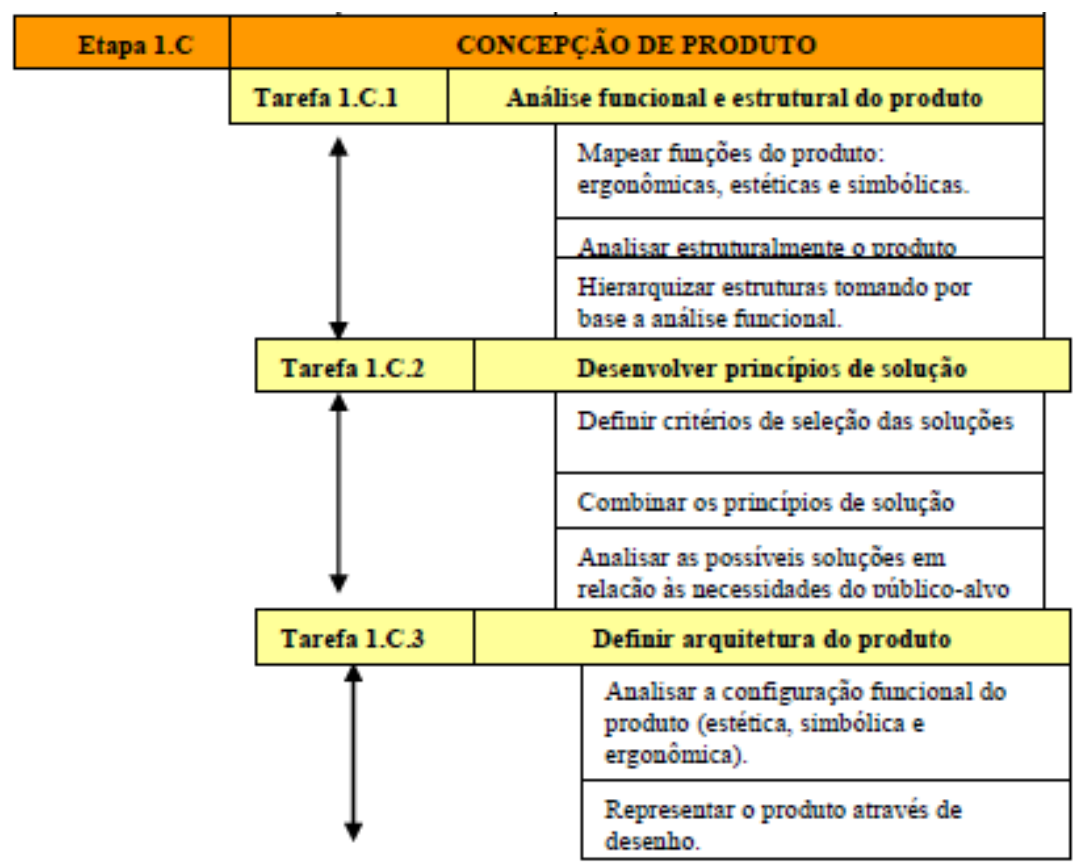

Analisar e escolher melhores soluções

Fonte: adaptado de Vicentini (2010).

\section{RESULTADOS E DISCUSSÃO}

Seguindo a diretriz metodológica proposta por Vicentini (2010), demos especial atenção ao Estudo de Viabilidade, nas informações sobre público-alvo, definições, possíveis concorrentes e interação produto-usuário. Assim, foram realizadas entrevistas com mães de crianças de 3 a 7 anos a fim de levantarem as necessidades e anseios ao adquirir um calçado infantil. Ao todo foram aplicados 40 (quarenta) questionários.

Buscando aplicar os conceitos de PBL combinados com a metodologia de Vicentini, também foram feitas várias dinâmicas com as crianças, em que estas puderam brincar e falar de suas histórias favoritas, e em que foram observados o ato mesmo de brincar. Isso foi de fundamental importância para compreensão, não só dos aspectos de usabilidade dos produtos, mas a aproximação com o universo infantil de maneira lúdica. Neste ponto a proposta do PBL do protagonismo do aluno ao construir seu conhecimento foi plenamente alcançada.

Assim, ficou bastante claro pela dinâmica com as crianças que o universo imaginário de uma floresta mágica, com aspectos lúdicos e de muita fantasia, que permitisse a interação da 
criança com o objeto, atenderia o requisito do público-alvo criança. O grupo de alunos empreendeu um levantamento inicial sobre crianças e suas fases de aprendizado segundo Piaget em que diz que o período Pré-Operatório, que vai de 2 a 7 anos, também pode ser encontrado dividido em dois períodos, sendo Simbólico e Intuitivo, e é o segundo do desenvolvimento infantil. Nesta fase a criança apresenta sinais de pensamento lógico em algumas situações. É também nesta fase que se desenvolve a linguagem, o desenho, a imitação e a dramatização. Segundo Bertolon (2012), é neste momento em que se inicia também o "fenômeno de 'dar vida' a objetos inanimados, como, por exemplo, querer dar comida aos brinquedos ou dar banho nos sapatos. Do meio para o fim desta fase as crianças necessitam de uma explicação para tudo". (BERTOLON, p. 12, 2012; BELLO, 1995).

A partir deste levantamento e definido o tema como "Floresta Mágica" passamos para a segunda etapa da metodologia a "concepção de produto". Neste ponto foram então elencados os requisitos de público-alvo conforme tabela 1 em que são definidas as especificações de um calçado infantil para que tenha segurança e conforto. A tabela abaixo, resume os aspectos ergonômicos que devem ser levados em consideração no projeto de calçados infantis de 3 a 7 anos, segundo as recomendações de Pracuch (2004) e Kohlrausch (2009).

Tabela 1: Características ergonômicas de calçado infantil

\begin{tabular}{|c|c|c|}
\hline & 3 a 5 anos & 5 a 7 anos \\
\hline Sola & $\begin{array}{l}\text { Flexível e um pouco mais } \\
\text { grossa }(6 \mathrm{~mm}) .\end{array}$ & $\begin{array}{l}\text { Absorção de impacto muito } \\
\text { necessário, flexível. }\end{array}$ \\
\hline Palmilha & $\begin{array}{l}\text { Plana e com forro } \\
\text { absorvente. }\end{array}$ & Plana e com forro absorvente. \\
\hline Cabedal & $\begin{array}{l}\text { Nas laterais deve ser firme } \\
\text { e sobre o dorso do pé macio } \\
\text { e flexível. }\end{array}$ & $\begin{array}{l}\text { Nas laterais deve ser firme e } \\
\text { sobre o dorso do pé macio e } \\
\text { flexível. }\end{array}$ \\
\hline Regulagem & Através de velcro. & Através de velcro. \\
\hline Biqueira & $\begin{array}{l}\text { Deve ser larga, para } \\
\text { acomodar bem os dedos, } \\
\text { ser feita de material mais }\end{array}$ & $\begin{array}{l}\text { Deve ser larga, para acomodar } \\
\text { bem os dedos, ser feita de } \\
\text { material mais duro e ter, no } \\
\text { mínimo, } 17 \mathrm{~mm} \text { de altura. }\end{array}$ \\
\hline
\end{tabular}




\begin{tabular}{|l|l|l|}
\hline Material & $\begin{array}{l}\text { duro e ter, no mínimo, 17 } \\
\text { mm de altura. }\end{array}$ & \\
\hline É recomendável que tenha & É recomendável que tenha boa \\
boa transmissão de calor, & transmissão de calor, resistência \\
resistência à abrasão, à abrasão, indeformabilidade. \\
indeformabilidade. \\
Material mais indicado é o & Plástico deve ser evitado. A sola \\
couro. Plástico deve ser & e o salto necessitam de material \\
evitado. A sola e o salto & impermeável. \\
necessitam de material & \\
impermeável. & \\
\hline
\end{tabular}

Fonte: adaptado de BERTOLON, 2012.

Tomando por base a tabela acima para realizar as análises funcionais e estruturais do produto foram então desenvolvidos os princípios de solução, ou seja, a etapa propriamente criativa do projeto, em que estes requisitos foram utilizados como basilares da criação. $\mathrm{O}$ princípio da abstração de funções foi largamente utilizado a fim de produzir o maior número de soluções possíveis para as funções primárias do calçado, que sejam: proteger os pés e facilitar o caminhar.

Também nesta etapa utilizou-se os conceitos de projeto modular e ficou definido que os calçados seriam também brinquedos, ou seja, permitiriam a criança uma interação maior com o mesmo, podendo transformá-lo em outro produto a partir da ação de desmontar e remontá-lo em outra combinação possível. As peças foram, então, projetadas de forma que poderiam atender este princípio.

O tema adotado permitiu uma ampla combinação de ideias, já que personagens da floresta, animais misturavam-se a fadas e duendes, este universo lúdico teve como resultado uma coleção de calçados e bolsas infantis modulares, cujas peças poderiam ser reposicionadas e transformados em brinquedos, ou seja, multifuncionais.

Dado o aspecto de inovação dos produtos foram solicitadas 4 (quatro) patentes de inovação de produtos com o tema Floresta Magica que receberam registro e um pedido de proteção de desenho industrial. Esses pedidos foram aprovados no INPI - Instituto Nacional de Propriedade Industrial. 
Os desenhos e fotos dos produtos não constam deste artigo pois ainda se encontram sob sigilo de patente.

\section{CONSIDERAÇÕES FINAIS}

É possível concluir que o uso de metodologias ativas para o desenvolvimento de produtos mostrou-se bastante adequada atendendo e até, no caso, excedendo as expectativas em relação ao aprendizado dos estudantes, já que teve como resultado concreto produtos que podem ser comercializados no mercado.

Outro ponto importante a ser levantado diz respeito a segmentação do público-alvo que direciona de maneira bastante eficiente as diretrizes do projeto, tornando-o mais objetivo tecnicamente abrindo espaço para a experimentação lúdica.

Relativamente às competências adquiridas, acreditamos que foram exploradas capacidades criativas, resolução de problemas em equipe, estratégias cognitivas interdisciplinares. A noção de sistematização e organização de informações também tiveram bastante relevância.

\section{REFERÊNCIAS}

AIRES, B.; AIRES, B.; BERTOLON, P.; OKASAKI, A.; SECOMANDI, M. P.; PIRES, B.; VICENTINI, C. R. G. COLEÇÃO DE CALÇADOS E ACESSÓRIOS INFANTIS. In Anais do XIX Colóquio de Moda, São Paulo, 2012.

BARBOSA, M. L. O. Expansão, Diversificação, Democratização: questões de pesquisa sobre os rumos do ensino superior no Brasil. In Caderno C R H, Salvador, v. 28, n. 74, p. 247-253, maio/agosto, 2015.

BOTTONI, A.; SARDANO, E., COSTA FILHO, G. B. Uma breve história da Universidade no Brasil: de Dom João a Lula e os desafios atuais. In Gestão universitária: os caminhos para a excelência. Porto Alegre: Penso, p. 19-42, 2013.

SILVA, F. J.; RABELO, A. A. Desenvolvimento de produtos infantis a partir da segmentação do mercado. Disponível em: < http://www.administradores.com.br/informese/producao-academica/desenvolvimento-de-produtos-infantis-a-partir-da-segmentacao-domercado/71/ >. Acesso em março de 2014.

ANDRADE, M. A. B. S. de; CAMPOS, L. M. L. Possibilidades e Limites da Prática da Aprendizagem Baseada em Problemas (PBL) no Ensino Médio. In Revista Enseñanza de Las Ciencias. Barcelona, número extra, VII Congresso, 2005. 
ARAÚJO, U. F.; ARANTES, V. Comunidade, Conhecimento e Resolução de Problemas: o Projeto Acadêmico da USP Leste. In ARAÚJO, U. F. \& SASTRE, G. Aprendizagem Baseada em Problemas no Ensino Superior. São Paulo: Summus, 2009, pp. 101-122.

BACK, N. Metodologia de projeto de produtos industriais. Rio de Janeiro: Guanabara Dois, 1983.

BELLO, J. L. P. A teoria básica de Jean Piaget. Vitória. 1995.

BERTOLON, P. Metodologia para o desenvolvimento de calçados infantis. In SIICUSP. São Paulo, 2012.

FAUSTINO, A. M. Aplicação da Aprendizagem Baseada em Problemas na Graduação de Enfermagem: Revisão de Literatura. In Revista Eletrônica Gestão \& Saúde, vol. 4, n. 1, 2013, pp. 1848-1859.

IIDA, I. Ergonomia: Projeto e Produção. São Paulo: Edgard Blücher, 2005.

KOHLRAUSCH, M. O melhor calçado para o seu filho. São Paulo: Gente, 2009.

LÖBACH, B. Design Industrial: bases para a configuração dos produtos. São Paulo: Edgard Blücher, 2001.

MARIBONDO, J.F. Desenvolvimento de uma metodologia de projeto de sistemas modulares aplicada a unidades de processamento de resíduos sólidos domiciliares. Florianópolis, 2000. Tese (Doutorado em Engenharia Mecânica). Programa de Pós-graduação em Engenharia Mecânica. Universidade Federal de Santa Catarina.

MIRANDA JUNIOR, U. J. P. de. Problem Based Learning como Metodologia Inovadora no Ensino de Graduação em Saúde. In Revista Port.Med. Geral Fam., Lisboa, 2016, p. 32.

PRACUCH, Z. O calce perfeito do calçado para crianças. 2004

RECH, S.R. Diretrizes Metodológicas para o projeto de produtos de moda no âmbito acadêmico. Bauru, 2003. Dissertação (Mestrado em Desenho Industrial). Programa de Pósgraduação em Desenho Industrial. Universidade Estadual Paulista Júlio de Mesquita Filho.

SANCHES, M. C. Moda e Projeto: estratégias metodológicas em design. 2018. São Paulo: Estação das Letras e Cores.

VICENTINI, C. R. G. Ferramentas e metodologia de projeto aplicados na criação de produtos para a indústria têxtil-confecção. Campinas, 2010. Tese (Doutorado em Engenharia Mecânica) Programa de Pós-Graduação da Faculdade de Engenharia Mecânica. Universidade Estadual de Campinas

VICENTINI, C. R. G.; DEDINI, F. G. Metodologia para o desenvolvimento de produtos de moda. In Anais do VIII Colóquio de Moda. Fortaleza, 2009. 
MARTINS, V. S., WOLFF, F. Competências em disciplinas de Projeto de Produto. In Estudos em Design. Rio de Janeiro, v. 23, n. 2 p. 37 - 58, 2015.

RODRIGUES, J. P.; PACHECO, R. A. Percepção de Estudantes da Escola de Artes, Ciências e Humanidades da Universidade de São Paulo acerca da Disciplina de Resolução de Problemas I e II In Rev. Grad. USP. São Paulo, vol. 2, n. 1, mar, 2017. 